\title{
Visual Ethnography, Thick Description and Cultural Representation
}

\section{Dipesh Kharel}

\begin{abstract}
The purposes of this paper are threefold: to cover historical, theoretical and methodological overview of visual ethnography (photography and film) as a research tool in studying culture; to examine visual ethnography as a means of cultural representation, and to discuss visual ethnographic method with Clifford Geertzis idea of "thick description". I hope to bring some clarity and consensus to our understanding how visual ethnography can be an adequate research tool for "thick description" and a study of culture. Furthermore, in this paper, I begin by seeing visual ethnography in the context to visual anthropology, photography, ethnographic film, and semiotics.
\end{abstract}

Keywords: Visual Ethnography, Thick Description, Photography and Ethnographic Film

\section{Introduction}

Visual information, particularly images, are ubiquitous in our society. They permeate our academic work, everyday lives, conversations (Pink, 2006), our imagination and our dreams (Edgar, 2004). According to Pink (2006), images are inextricably tied up with our daily life, personal identities, narratives, lifestyles, cultures and societies, as well as with definitions of history, space and truth. Ethnographic research is likewise intertwined with visual images and socio-cultural representations (Pink, 2006). After conducting visual ethnographic fieldwork, when ethnographers produce photographs or video as a research product, these visual texts as well as the 


\section{8| Dipesh Kharel}

experience of producing and discussing them, became part of their ethnographic knowledge. 'In ethnography images are as inevitable as sounds, smells, textures and tastes, words or any other aspect of culture and society' (Pink, 2006, p. 21). Banks (2007) points out two stands of visual ethnography which contrast to each other: on the one hand the use of image to study society and on the other, the sociological study of images. Indeed, visual ethnography's scope is wide-ranging, including the production and analysis of still photos and films, the study of art and material culture, and the investigation of gestures, facial expression and spatial aspects of behavior and interaction (Banks et al. 1997).

Banks (2007) states that there are two good reasons to incorporate the analysis of images paintings, photographs, film, videotape, drawings, diagrams and a host of other images. The first good reason is that images are ubiquitous in society, and because of this some consideration of visual representation can potentially be included in all studies of society. The second reason that, a study of images or one that incorporates images in the creation or collection of data might be able to revel some sociological insight that is not accessible by any other means.

The goals of this paper are to (1) cover historical, theoretical and methodological overview of visual ethnography (photography and film) as a research tool in studying culture; (2) examine visual ethnography as a means of cultural representation, and (3) discuss visual ethnographic method with Clifford Geertz's idea of "thick description". The term "thick description" became part of the qualitative researcher's vocabulary when Geertz borrowed Ryle's (1971) philosophical term to describe the work of ethnography. Geertz pronounced that ethnographer's task is that of explaining culture through thick description, which provides a detail knowledge of how people feel, think, imagine and perceive their world. Following Geertz's idea of "thick description", I hope to bring some clarity and consensus to our understanding how visual ethnography can be an adequate research tool for "thick description" and a study of culture. In this paper, I begin by seeing visual ethnography in the context to visual anthropology, photography, ethnographic film, and semiotics. 


\section{9| Dipesh Kharel}

\section{Photography in Ethnographic Research and Cultural Representation}

In her influential book Anthropology and Photography (1994), Elizabeth Edwards describes that photography, since its beginnings, has been a resource for anthropologists in the recording of ethnographic data. By using photography in ethnographic fieldwork, many ethnographers recognized that the photographic image is 'true' in the sense that it holds a visual trace of a reality the camera was pointed at. Banks (2007) states that photography has been used to document and represent knowledge about society since the beginning of modern anthropology and sociology in the nineteenth century. Many visual research scholars such as MacDougall (1997), Banks (2007), and Harper (1998) remark that photographs were a prominent feature of ethnographies until the 1930s. For example, Hattersley's The Baganda at Home (1908), contains eighty photographs (MacDougall, 1997, p. 281). Traditionally, photography was used in conjunction with more traditional forms of anthropological information that was considered the reflexive and critical nature of the photographic "way of seeing" within anthropology (Edwards, 1994). MacDougall (1997, p. 279) remarks that 'feature such as nakedness and the use of animal products (feathers, skin, hair and bones), communicated by means of photographs and visible artifacts in museum and magazine illustrations, became symbolic indicators of how close people were to nature.'

In his essay An Argument for Visual Sociology (1998), Harper mentions that photography's role in this early history is well told by Elizabeth Edwards (1994), who notes that photography was first thought of 'as a simple...truth -revealing mechanism' (1998, p. 21). According to Harper (1998), the book, Balinese Character (Bateson and Mead, 1942) showed the potential of visual ethnography in the study of culture. Harper quotes Bateson and Mead (1942) as follow:

we are attempting a new method of stating the intangible relationship among different types of culturally standardized behavior by placing side by side mutually relevant photographs...By the use of photographs, the whole ness of each piece of behavior can be preserved, while the special cross referencing desired can be obtained by placing the series of photographs on the same page. (1998, p. 21) 


\section{0| Dipesh Kharel}

From Harper's (1998) description and explanation, it can be argued that Bateson and Mead offered a new model for integrating image and text. The significance of their project is that the photographs were regarded as a part of the process of observation. Bateson and Mead both spent several years in the field, and completed ethnographic studies before they then turned to the subject with their cameras. The theories they explored with photographs were grounded in anthropological knowledge (see Harper, 1998). Methodologically, to make the photographs 'intellectually denser', Becker (1974) suggests the photographer must become conscious of the theory that guides one's photography. That theory may be 'lay theory'-taken for granted assumptions about the world is organized-or it may be 'deep, differentiated and sophisticated knowledge of the people and activities they investigate---for photographic projects concerned with exploring society it means learning to understand society better' (Becker, 1974, p. 11). Banks (2007) mentions that researcher must be sensitive to local perception of photography and should always try and establish rapport with people before taking photographs or shooting video.

"A.C. Haddon and the representation of the past" is one of the best case studies in Banks's book Using Visual Data in Qualitative Research (2007, p. 19), which is crucial to understand how photography can be used for socio-cultural representation. Banks (2007) says that colonial officials and ethnologists were exploring the use of photography as a tool to document and make sense of other societies. For example, through photography of caste 'types' in India it was hoped that visual attributes of bodily morphology, dress and associated artifacts would reveal inner sociological truths (Banks, 2007). According to Harper (1998), in their book Balinese Character, Bateson and Mead (1942) illustrated photography as ethnography. Bateson and Mead were able to represent the intangible culture of Balinese through their photographic records. Harper quotes Bateson and Mead (1942) as follow:

(our several monographs on the Bali) all attempted to communicate those intangible aspects of culture which had been vaguely referred as its ethos. As no precise scientific vocabulary was available, the ordinary English words were used, with all their weight of culturally limited connotations, in an attempt to describe, the way in which the 


\section{1| Dipesh Kharel}

emotional life of these various South Sea people was organized in culturally standardized form...(1998, p. 21)

However, Hastrup (1992) argues that some anthropologists have not taken more readily to the camera as research instrument and to photography as a means of communicating ethnographic knowledge. She does this by working out in detail the difference between pictorial images and words as way to transmitting ethnographic knowledge (Crawford et al. 1992, p.3). By telling her own fieldwork experience of a remarkable cultural event "ram exhibition" in Iceland she lays down a powerful and uncompromising challenge to those who believe that photos can speak louder than words for anthropologist. But many anthropologists, such as MacDougall (1997) and Pinney (1992), do not agree with her idea. They argue that photographs do not only speak louder than words but also offer too much meaning, especially if not authorized by its explanatory caption, offers the viewer almost total freedom to follow up or perhaps better, 'construct' any number of meaning from those potentially contained within it. In Banks's sense (2007) photographs are open documents where viewers can learn and construct layers of cultural meaning. He point out that photographs can only represent culture of people or only represent part of the story if they are ideologically constructed rather than naturally taken.

\section{Film in Ethnographic Research and Cultural Representation}

Banks (2007, p. 28) mentions that 'by 1901, the anthropologist Baldwin Spenser was filming aboriginal dances in Australia, and over the next two decades or so a number of anthropological expeditions were equipped with a film camera for documenting the customs and habits of the natives.' In Western Europe and America a new direction come about in 1922 when the American explorer and filmmaker Robert J. Flaherty publicly released his influential Nanook of the North (Banks, 2007, p. 28). MacDougall (1997) remarks that Flaherty's Nanook of the North attempts to realistically portray Inuit people (although he actually used actors and staged a good deal of the production) with valuable pictures of a little-known way of life. Flaherty's achievements in Nanook of the North provide an interesting account of Inuit technology, the ways in which their life was adopted to the environment and the uniqueness and relative autonomy of their cultural system (Banks et al. 1997). From several 


\section{2| Dipesh Kharel}

examples of ethnographic films, it seems that the actual medium of "film" is strongly associated with early ethnographic studies.

An ethnographic film emerged in the 1960s as an important tool for research in the domain visual anthropology, when filming human groups in society (MacDougall, 1997). In his essay The Visual in Anthropology (1997), MacDougall describes that a film camera has become as 'an indispensable piece of anthropological apparatus' to record the everyday life of people. In Banks's idea the use of film in social research has been increased because of some theoretical shift, at lest in some parts of some social sciences away from positivism and towards interpretivism (2007, p. 29). Specifically, Banks argues that a film tool has become effective to record social evidences when there has been shift in social science, from language and linguistically derived models of society to studies oriented towards the body, to music and dance, and to feeling, emotion and memory.

In her introduction to Principles of Visual Anthropology (Hockings 1995), Margaret Mead has described that film eye is more perfect than the human eye, and that therefore; it provides a more precise records of happening. Mead has emphasized that in visual ethnography camera can be used as a research tool to record real events and explore the cultural knowledge. This idea can be supported by MacDougall's concept of ethnographic film. He says, 'film is capable of presenting complex networks of images within which a variety of ambiguous cultural construction and resonances are understood' (1998, p. 80). I have experienced this through my own visual ethnographic fieldwork (2006) in the Thami village, Nepal. I realized that my field notes about slate mining never provided me with the understanding of the mining process that the rough footage provided. Thami slate porters and miners find it difficult to explain their work. They have unique words and idioms to describe the process of slate mining and to define the slate structure, which are very difficult to explain to audiences without visual means. I therefore thought that my film (A life with Slate, 2006) would provide a better anthropological understanding of knowledge in the context of slate mining and carrying. For about four months I was engaged with the daily life of slate miners and porters, but I still do not find it easy to explain to readers about their knowledge of slate mining in the way that I feel the film can, much more effectively. 


\section{3| Dipesh Kharel}

According to Banks (1998), until recently, the visual ethnography was understood by many scholars to have a near exclusive concern with the production and use of ethnographic film. In recent years, however, visual ethnography has come to be seen as the study of visual forms and visual system in their cultural context (Banks, 1998). While the subject matter encompasses a wide range of visual forms- film, photography, ' tribal' or 'primitive' art, television and cinema, computer media- all are united by their materials presence in the physical world. MacDougall emphasizes that if film is to be more than a method in anthropology, more than a medium of public relations, more than the stepping-stone to a career in the media, the focus must be on the contribution that film can make to anthropology as a theoretical discipline (Banks et al. 1997, p. 5).

Methodologically, Banks (2007) emphasizes that, we should broaden the frame of a camera as well as our research framework while conducting ethnographic fieldwork and observe the daily lives of people in particular socio-cultural setting. In visual ethnographic fieldwork, the importance of widening a camera frames is to document a complete narrative of social life and social interaction. As Banks (2007, p.13) puts it: In visual research the frame initially appears to be the frame around the image as published or experienced, but further investigation often show that the frame needs to be considerably broadened.'

The use of film as a research tool for use in anthropological fieldwork and later analysis has been greatly facilitated in recent years. First, the development of cheap, lightweight video technology has lowered the costs and difficulty of conducting visual ethnography (Banks et al. 1997, p. 5). From Banks (1998) description and explanation of anthropology and visual system, it can be also analyzed that the scope of visual ethnography has became interdisciplinary because of an apparent shift in anthropology away form the study of abstract system (kinship, economic system and so forth) and towards a consideration of human experiences. This has resulted in a focus on body, the emotions, and the senses. In addition, the visual ethnography was to be valued for giving some insights into the experience of being a particular in another culture, permitting largely Euro-American audiences to see life through the eyes of non-European others (Prosser, 1998). 


\section{4| Dipesh Kharel}

There are different interpretations of film based on the audience's socio-cultural background, professional area, and level of film literacy. In Morley's idea (1980), different group of people will have access to different discursive resources for decoding media message. According to Crawford et al. (1992, p.5), ethnographic film can be said to reach its audience by means of explanatory devices: the experimental mode invites the audiences to understand and sense other cultures by emphasizing analog forms of representation open to interpretation. In that sense, ethnographic films are open to audiences constructing their own meanings based on their own observation of the film. The meaning can be produced on any level: emotional, ideological or practical level. I have experienced this during my film A Life with Slate screening at international film festivals. I found several different interpretations of the film based on the audience's socio-cultural background, professional area, and level of film literacy. In the words of MacDougall, ethnographic films are extremely powerful in conveying the plurality of the world. According to Weakland (1995, p.55), films themselves are rich and complex. For instance, while film studies have primarily been concerned with examining dialogue and the action depicted, valuable information may also reside in music, sounds effects and technical aspects of films such as camera usage. For instance, in my film screening audiences got lot of information from the landscape. The difficult paths over the mountain where the slate porters make slate carrying trips gave an idea of the hardship of their lives and their embodied knowledge.

\section{Visual Ethnography and Clifford Geertz's Idea of "Thick Description"}

According to Crawford et al. (1992), the visual particularly film as research method, recoding, probing, and sometimes being as agent or actor in an event allows us, through the addition of subtitles, to form a better understanding of the nature of the inquiry and therefore of the quality of the material obtained. 'It makes field enquiries more accessible, and 'thicker' in Geertz's sense' (Crawford et al. 1992, p.6).

Geertz (1973) believed that the data of anthropological writing was "really our own construction of other people's constructions of what they and their compatriots are up to" (1973, p. 9). Therefore, for 


\section{5| Dipesh Kharel}

a reader of ethnographic work to gauge for herself or himself the credibility of the author's interpretations, the context under which these interpretation were made must be richly and thickly described. "Thick description" originated as a qualitative research tool for ethnographers engaged in participant observation research (Geertz, 1973). Following Geertz (1973), Denzin (1989) highlights the features of "thick description" as follows: (1) It gives the context of an act; (2) it states the intentions and meanings that organize the actions; (3) it traces the evolution and development of the act; (4) it presents the action as a text that can be interpreted. (1989, p. 33). Ponterotto (2006) uses the metaphor of a tree to explain the interconnection of three concepts: "thick description," "thick interpretation" and "thick meaning". The "thick description" constitutes the roots of the tree that nourish and feed "thick interpretation", represented by the solid trunk of the tree, which in turn feeds the branches and leaves of the tree, which represent the "thick meaning". Geertz (1973) remarks that anthropology's task is that of explaining cultures through thick description which specifies many details, social structures, social actions and meanings, and which is contrast to "thin description" which is a factual and superficial account without any interpretation. According to Geertz (1973) "thin description" is not only an insufficient account of an aspect of a culture; it is also a misleading one. Therefore, Geertz (1973) suggests that an ethnographer must present a "thick description" which is composed not only of facts but also of commentary, interpretation and interpretations of those comments and interpretations. He points out:

The claim to attention of an ethnographic account does not rest on its author's ability to capture primitive facts in faraway places and carry them home like a mask or carving, but on the degree to which he is able to clarify what goes on in such places, to reduce the puzzlement — what manner of men are these? (1973, p.16)

According to Crawford et al. (1992), in visual ethnographic research environment, Geertz's idea of "thick description" can be achieved by images, gestures, or sequences that convey meaning. Thickness is created by the ability of the visual description to transmit what is really being 'said.' In ethnographic filmmaking, "thick descriptions" result from what has been recorded and edited. Mead (1995) remarks that a camera can be used to record thick descriptions of informants 


\section{6| Dipesh Kharel}

and their socio-cultural context through their own voices and activities, based on their understandings of their world, which may not possible with verbal descriptions. According to MacDougall (1998), ethnographic films are effective to covey subjective understanding. He remarks, "the subjective voice in ethnographic film" is part of the construction of the subject (1998, p. 25).

So, it can be argued that film images that are drawn from the 'other culture' itself speak about the culture in detail and provide "thick description" (Geertz, 1973). Crawford et al. (1992) has emphasized that through the ethnographic films, audiences can observe situations, feel movements, and make sense of events. With reference to John Collier (1986), Pinney (1992, p. 27) remarks that 'only film or video can record the realism of time and motion of the psychological reality of varieties of interpersonal relations.' The significance of a film records in ethnographic research can be illuminated by Emilie de Brigard's remarks (1995, p. 38): 'The history of ethnographic film is rich in example of film's unique capacity to record the multileveled nature of events, of its usefulness in teaching new ways of seeing, and of its power to evoke deeply positive feeling about mankind by communicating the essence of a people.'

According to Loizos (1992), with ethnographic film, we normally do get words in addition to the visual record that can provide "thick description" to communicate ethnographic knowledge. Loizos (1992) examines 'a number of modalities with which documentary films communicate to up' (1992, p. 50), all of which depend up the close integration to pictures and words. The 'documentation modality' for example, is that aspect of film which works to record to document what happens in front of lens and microphone (Loizos, 1992, p. 51). In Loizos's sense films do succeed in communicating "thick description" and ethnographic knowledge, sometimes even more effectively than written ethnography.

\section{Conclusion}

From the brief historical, theoretical and methodological overview of visual ethnography, it can be assumed that photography and film form an important part of visual ethnography both in its contemporary practice and its historical origins. As Pink (2006) mentions, the potential use of visual tools in research can be 


\section{7| Dipesh Kharel}

harnessed by engaging visual anthropology with its wider contexts, including: 1) the increasing use of visual research methods across the social sciences and humanities; 2) the growth in popularity of the visual as methodology and object of analysis within mainstream anthropology and applied anthropology; and 3) the growing interest in 'anthropology of the senses' and media anthropology.

As I have reviewed above, MacDougall (1997) and Banks' (2007) ideas of visual ethnography, there is a duality of focus in visual ethnography: on the one hand, the visual anthropology that studies visible cultural forms. On the other hand is the visual ethnography that uses the visual media to describe and analyze culture with interdisciplinary approach. Therefore, it can be said that visual ethnography is concerned with the whole process of anthropology from the recording of data, through its analysis to the dissemination of the results of research. Visual anthropologist include a coalition of people who find film relevant to their work in anthropology and who have in common an interest in film as a recording medium to provide "thick description" (Geertz, 197, p. 39). Anthropologist of art, dance, material culture, ethnology and non-verbal communication have characteristically used film and photography as tools in their research.

Traditionally, the study of visual forms produced by the anthropological subjects had been conducted under the label of the anthropology of art. However, over the last three decades ethnographers have given serious consideration to using images to enhance understanding of the human condition (Prosser, 1998). Ethnographers/ anthropologists have begun to appreciate the indigenous art, Euro-American film and photography, local TV broadcast output and so forth are all 'visual system'- culturally embedded technologies and visual representational strategies that are amenable to anthropological analysis. They use images not only as representations of the objective world but also to communicate "thick description" thick interpretation" and thick meaning" Denzin (1989).

\section{Acknowledgements}

I would like to express my sincere thanks and grateful appreciation to my supervisor Professor Nawa Katsuo at the University of Tokyo, 


\section{8| Dipesh Kharel}

Japan, for his remarkable comments and recommendations on my research. My research has carried out with financial assistance of JSPS fellowship, Japan. My sincere thanks go to JSPS.

\section{References}

Banks, M. (2007). Using Visual Data in Qualitative Research. Yard, 55 City Road, London ECIY 1SP: SAGE Publications Ltd. 1 Oliver's.

Banks, M. and Morphy, H. (1997). (eds) Rethinking Visual Anthropology. New Haven and London: Yale University Press.

Bateson, G. and Mead, M. (1942). Balinese Character: A Photographic Analysis. New York: New York Academic of Sciences.

Becker, H. S. (1994). "Photography and Sociology", Studies in the Anthropology of Visual Communication . Northwestern University Press.

Brigard, E. de. (1995). "The History of Ethnographic Film" in Principles of Visual Anthropology. Printing: RatzlowDruck, Berlin.

Crawford, P. I. (1992). "Film as discourse: the invention of anthropological realities" in Film as Ethnography. Edited by Crawford, Peter Ian and Turton, David. Manchester: Manchester University Press.

Crawford, P. I. and Turton, D. (1992). (eds) Film as Ethnography. Manchester University Press.

Denzin, N. K. (1989). Interpretive Interactionism. Newbury Park. CA. Sage.

Edgar, I. (2004). "Image work in ethnographic research", in Working images: Visual Research and Representation in Ethnography. Edited by S. Pink, L. Kurti and A.L. Afonso. London: Routledge, pp. 90-106.

Edwards, E. (1994). Anthropology and Photography 1860-1920. New Haven: Yale University Press, in association with the Royal Anthropological Institute, London.

Harper, D. (1998). "An argument for visual sociology” in ImagedBased Research: A Sourcebook for Qualitative Researchers. Edited by J. Prosser. London: Falmer Press.

Hastrup, K. (1992). “Anthropological visions: some notes on visual 


\section{9| Dipesh Kharel}

and textual authority" in Film as Ethnography. Edited

by Crawford, Peter Ian and Turton, David. Manchester:

Manchester University Press.

Grimshaw, A. (2001). The Ethnographer's Eye: Ways of seeing in anthropology. Cambridge University Press.

Geertz C. (1973). Thick description: Toward an Interpretive Theory of Culture. In Interpretations of Cultures. New York: Basic Books.

Loizos, P. (1992). Admissible evidence? Film in anthropology in Film as Ethnography. Edited by Crawford, Peter Ian and Turton, David. Manchester: Manchester University Press.

MacDougall, D. (1998). Transcultural Cinema. Princeton: Princeton University Press.

MacDougal, D. (1997). The visual in anthropology. In Rethinking Visual Anthropology. Edited by Marcus Banks and Howard Morphy. New Haven and London: Yale University Press.

MacDougal, D. (1992). "Complicities of style" in Film as Ethnography. Edited by Crawford, Peter Ian and Turton,

David. Manchester: Manchester University Press.

Mead, M. (1995). "Visual Anthropology in a Discipline of worlds" in Principles of Visual Anthropology. Printing: RatzlowDruck, Berlin.

Martinez, Wilton.(1992). Who construct anthropological knowledge? Towards a theory of ethnographic film spectatorship. In Film as Ethnography. Edited by Crawford, Peter Ian and Turton, David. Manchester: Manchester University Press.

Pink, S. (2006). The future of Visual Anthropology: Engaging the Senses. Rutledge, 2 Park Square, Milton Park, -Abingdon, Oxon OX14RN.

Pinney, C. (1992). The lexical spaces of eye-spy. In Film as Ethnography. Edited by Crawford, Peter Ian and Turton, David. Manchester: Manchester University Press.

Morley, D. (1980). The Nationwide Audience: Structure and Decoding. London: BFI. ISBN 0-85170-097-7.

Ponterotto, J.G. (2006). Brief Note on the Origins, Evolution, and Meaning of the Qualitative Research Concept "Thick Description”. The Qualitative Report. Volume 11 Number 3 September.

Prosser, J. (1998). The status of image-based research. In ImageBased Research: A Sourcebook for Qualitative Researchers. 
160| Dipesh Kharel

Edited by Prosser, J. London: Falmer Press.

Ryle, G. (1971). Collected paper. Volume II collected essays, 19291968. London: Hutchinson.

Weakland, J. H. (1995). "Feature Films as Culture Documents" in Principles of Visual Anthropology. Printing: RatzlowDruck, Berlin. 